\title{
Effect of Single Walled Carbon Nanotubes (SWCNTs) Addition during Field Activated Sparck Plasma Sinter (FASPS) in the Ceramics Matrix Nanocomposites $\left(\mathrm{Mo}_{2} \mathrm{C}\right)_{1-\mathrm{x}}(\mathrm{TiC})_{\mathrm{x}}(2 \leq \mathrm{x} \leq 4)$ : Physical, Mechanical Properties and Sintering Behaviour
}

\author{
Badis Bendjemil ${ }^{1,2, *}$, Jacques G. Noudem ${ }^{3}$, Mohamed Mouyane ${ }^{4}$, Jérôme Bernard ${ }^{4}$, Jean Michel Reboul ${ }^{4}$, \\ Yannick Guhel ${ }^{4}$, David Houivet ${ }^{4}$ \\ ${ }^{1}$ DGM, FST, University of 8 Mai 1945 of Guelma, 24000 Guelma, Algeria \\ ${ }^{2}$ LASEA, DC, FS, University of Badji Mokhtar, 23000 Annaba, Algeria \\ ${ }^{3}$ ENSICAEN, 6, Boulevard Maréchal Juin, CS 4505314050 Caen cedex 04, France \\ ${ }^{4}$ LUSAC, EA 4253, 60 rue Max Pol Fouchet, CS 20082, University of Caen Normandy, 50130 Cherbourg-Octeville, France
}

Copyright $\bigcirc 2017$ by authors, all rights reserved. Authors agree that this article remains permanently open access under the terms of the Creative Commons Attribution License 4.0 International License

\begin{abstract}
Nanocomposites are wear resistant materials used in cutting tool applications. The materials are composed of ultrafine powder hard phase grains surrounded by a tough binder phase carbon nanotubes $\left(\mathrm{Mo}_{2} \mathrm{C}\right)_{1-\mathrm{x}}(\mathrm{TiC})_{\mathrm{x}} \quad(2 \leq \mathrm{x} \leq 4) / / 1 \mathrm{Wt} \% \quad$ SWCNTs. Composite bicarbide $\mathrm{Mo}_{2} \mathrm{C}-\mathrm{TiC}$ was rapidly synthesised and simultaneously consolidated by Field activated sintering technique (spark plasma sintering) at which the extensive volume expansion occurred as a function of the volumic fraction from 20 to $40 \mathrm{vol} . \%$ of TiC powders and $1 \mathrm{Wt} . \%$ of SWCNTs as reinforcement of the CMNC's. The sintered powder mixture was examined by XRD patterns, the morphology of the obtained phase was observed by SEM and the phase compositions in different regions were analyzed by EDX. The composites were processed using Field Activated Sintering Technique, spark plasma sintering (SPS) at temperatures in the range of $1700-1800^{\circ} \mathrm{C}$ with addicting of SWCNTs. The effects of SWCNTs addition on phases morphology, microstructure hardness and fracture toughness of the nanocomposite were investigated. The best product contained $1.0 \mathrm{Wt} . \%$ SWCNTs from $\left(\mathrm{Mo}_{2} \mathrm{C}\right)_{1-\mathrm{x}}(\mathrm{TiC})_{\mathrm{x}}, x=0.2$ which was sintered at $1700^{\circ} \mathrm{C}, 70 \mathrm{MPa}$ for $10 \mathrm{~min}, \mathrm{M}_{0.8} \mathrm{~T}_{0.2} / 1 \mathrm{Wt} \%$ SWCNTs exhibit a better density, highest hardness and a good ductility. Relative densification was achieved $99.5 \%$ from the theoretical and a good mechanical properties like hardness and fracture toughness $\left(\mathrm{K}_{\mathrm{IC}}=5.6 \mathrm{Mpa} \mathrm{m}^{1 / 2}\right)$ are enhanced. The results were confirmed using Raman spectroscopy.
\end{abstract}

Keywords $\quad\left(\mathrm{Mo}_{2} \mathrm{C}\right)_{1-\mathrm{x}}(\mathrm{TiC})_{\mathrm{x}} \quad(2 \leq \mathrm{x} \leq 4) / / \quad 1 \quad \mathrm{Wt} \%$ SWCNTs, Ceramics Matrix Nanocomposites (CMNC's), Field Activated Sintering Technique (SPS), Physical Properties, Mechanical Properties, Wear Resistant, Microstructure-final, Raman Scattering

\section{Introduction}

Nanomaterials (defined as being in the size range $1-100 \mathrm{~nm}$ in at least one dimension) have been the subject of extensive research in recent years due to their extraordinary properties over their conventional counterparts. For more than two decades, the topic of nanomaterials' development has been widely investigated by many researchers aiming at exploring their potential and finding suitable applications. Ultimately, they proved to be beneficial in several applications in areas like surface engineering, drug delivery, analytical chemistry, bio encapsulation, Nano composite as well as in electronic, magnetic, optical, and mechanical devices.

These applications do stimulate a great deal of research interest amongst institutions and companies aiming at capitalizing on their potential. However, there are still a number of difficulties when it comes to processing of these nanomaterials especially in fabricating final products as these nanomaterials may lose their crystallite size along the path of processing. These problems have to be tackled 
before the potential of nanoparticles or nanomaterials can be fully realized [1]. The problem of undesirable grain growth is persistent in the sintering/consolidation processes of several advanced materials that usually gain their importance and thus potential properties from their reduced crystallite sizes.

The composite $\left(\mathbf{M o}_{2} \mathbf{C}-\mathbf{T i C}\right)$ based hard metals or cemented carbides represent an important class of materials used in a wide range of industrial applications which primarily include cutting/drilling tools and wear resistant components. The introduction and processing of nanostructured composite made of $\mathbf{M o}_{2} \mathbf{C}$-TiC based carbon nanotubes and their subsequent consolidation to produce dense components have been the subject of several investigations. One of the attractive means of producing this class of materials is by mechanical alloying technique. However, one of the challenging issues in obtaining the right end-product is the possible loss of the nanocrystallite sizes due to the undesirable grain growth during powder sintering step. The present paper highlights some key issues related to powder synthesis and sintering of composite $\mathrm{Mo}_{2} \mathrm{C}$-TiC -based nanostructured materials using mechanical alloying. The path of directly consolidating the powders using nonconventional consolidation techniques will be addressed and some light will be shed on the advantageous use of such techniques. Carbon nanotubes-bonded hard nanomaterials will be principally covered in this work along with an additional exposure of the use of other binders in the $\mathrm{Mo}_{2} \mathrm{C}$-TiC-based hard nanomaterials.

Table 1. Overview of $\boldsymbol{R S}$ process

\begin{tabular}{|c|c|c|c|}
\hline Process name & $\begin{array}{c}\text { Reported applied current } \\
\text { characteristics }\end{array}$ & Reported applied current characteristics & Reference \\
\hline Electric sintering & & & {$[5]$} \\
\hline Spark sintering & $\begin{array}{c}A C \\
\text { Combination of } A C \text { and } D C \\
\text { Pulsed } D C+D C \\
\text { Pulsed } D C\end{array}$ & $\begin{array}{c}\text { Japax Scientific Corp } \\
- \\
- \\
\text { Sumitomo Coal Mining Co. }\end{array}$ & $\begin{array}{c}{[6]} \\
{[7,8]} \\
{[9]} \\
{[10]}\end{array}$ \\
\hline Electric discharge sintering & $\begin{array}{c}\text { Combina. of low Frequ. } A C \text {, } \\
\text { Highfrequ. AC and/or DC } \\
\text { Pulsed }\end{array}$ & - & [11] \\
\hline Spark discharge sintering & - & - & [13] \\
\hline $\begin{array}{c}\text { Electrically activated pressure } \\
\text { sintering }\end{array}$ & $\begin{array}{c}\text { Combination of } \\
\text { low-frequency } \\
\text { AC and/or } D C+\text { high } \\
\text { frequency } A C \\
\end{array}$ & - & [14] \\
\hline $\begin{array}{c}\text { Electrical discharge-type activated } \\
\text { pressure sintering }\end{array}$ & $\begin{array}{l}\text { Combination of } \\
\text { low-frequency } \\
\text { AC and/or DC }+ \text { high } \\
\text { frequency } A C \\
\end{array}$ & - & [15] \\
\hline Spark isostatic pressing (SIP) & Superimposed $A C+D C$ & - & [16] \\
\hline Electric pulse sintering & Pulsed & - & [17] \\
\hline Direct resistance sintering & $A C$ & - & [18] \\
\hline Resistance sintering & $\begin{array}{c}- \\
A C \\
\text { Combination of } A C \text { and } D C\end{array}$ & $\begin{array}{l}- \\
- \\
-\end{array}$ & $\begin{array}{l}{[19]} \\
{[20]} \\
{[21]}\end{array}$ \\
\hline $\begin{array}{l}\text { (Direct) Electric resistance } \\
\text { sintering }\end{array}$ & $A C$ & - & [22] \\
\hline Plasma activated sintering (PAS) & $\begin{array}{c}\text { Pulsed } D C+D C \\
\text { Pulsed } D C+D C \\
\text { Pulsed }+D C . \\
\text { DC } \\
\text { Pulsed } D C \\
\end{array}$ & $\begin{array}{c}- \\
\text { Sodick Co. Ltd. } \\
\text { Materials Modification IncSodick Co. Ltd } \\
\text { Sumitomo Coal Mining Co Ltd. }\end{array}$ & $\begin{array}{l}23] \\
{[24]} \\
{[25]} \\
{[26]} \\
{[27]}\end{array}$ \\
\hline Electric current sintering & - & - & [28] \\
\hline Plasma assisted sintering (PAS) & Pulsed DC $+D C$ & Sodick Co. Ltd. & [29] \\
\hline Spark plasma sintering (SPS) & $\begin{array}{l}\text { Pulsed DC } \\
\text { Pulsed }+ \text { DC } \\
\text { Pulsed } \\
\text { Pulsed DC } \\
\text { DC } \\
\text { AC } \\
- \\
\text { Pulsed DC. } \\
\text { Pulsed DC }\end{array}$ & $\begin{array}{c}\text { Summit. Coal Mining Co. Ltd } \\
\text { Sodick Co. Ltd. } \\
\text { Izumi Technology Co. Ltd. Izumi Technology Co. } \\
\text { Ltd. Izumi Technology Co. Ltd. } \\
- \\
\text { FCT Systeme GmbH } \\
\text { Eltek Co. Ltd } \\
\text { FCT Systeme GmbH }\end{array}$ & $\begin{array}{l}30] \\
{[31]} \\
{[32]} \\
{[33]} \\
{[34]} \\
{[35]} \\
{[36} \\
{[37]} \\
{[38]}\end{array}$ \\
\hline
\end{tabular}


In order to summarize some of the relevant information reported so far, the various $\boldsymbol{R S}$ process used for successful synthesis of this hard nanocomposites are historically listed in Table 1 along with the corresponding reported applied current characteristics and the apparatus adopted. It can be clearly seen that, as already mentioned, diverse current waveforms and/or apparatus are adopted for the same process. In the last column of Table 1 the references indicate where, at our best knowledge, the process name/acronym, and for each process name/acronym, the different applied current waveforms or adopted apparatus were reported for the first time. It should be noted that the names $\boldsymbol{E} \boldsymbol{C A S}$ [2], and field activated sintering technique (FAST) [3] were introduced to designate the consolidation methods based on the application of a electric field/current regardless their waveforms, while pulse electric current sintering (PECS) was used by some authors as a generalization of $\boldsymbol{R S}$ methods which involve the application of a pulsed electric current [4]. It should be pointed out once more that the applied characteristics and/or the apparatus adopted were in some cases not specified. Therefore, Table 1 should not be considered as comprehensive of all possible combinations of process name, applied current and apparatus adopted in this research field.

In this work the studies of $\left(\mathbf{M o}_{2} \mathbf{C}\right)_{1-x}-(\mathbf{T i C})_{x}(2 \leq x \leq 4) / / 1$ Wt \% SWCNTs based NCMC 's, sintered at low pressures (70 MPa - provided by field activated sintering technique (SPS) are presented. A fine $\left(\mathrm{Mo}_{2} \mathrm{C}\right)_{1-\mathrm{x}}-(\mathrm{TiC})_{\mathrm{x}}$ $(\mathbf{2} \leq \mathbf{x} \leq \mathbf{4}) / /$ powder grade was chosen as the matrix material The use of only $20 \mathrm{vol.} \%$ of TiC with $1 \mathrm{Wt} \%$ SWCNTs reinforcements aims to increase physical and mechanical resistance of the(NCMC's). Moreover, the relatively small content of dispersed phase decreases the probability of direct contacts between their particles. The (NCMC's) sintering temperature is higher than $1700{ }^{\circ} \mathrm{C}$. In the case of low temperature $\boldsymbol{S P S}$ sintering process weak bonding between the TiC grains may yield to low micro hardness and high fracture toughness.

\section{Experimental}

Commercially available powders of $\mathbf{T i C}(<\mathbf{2} \boldsymbol{\mu m}, \mathbf{9 9 . 8} \%$ purity, Sumitomo Sitix, Co. Ltd., Japan, $\mathbf{M o}_{2} \mathbf{C}(<2 \mu \mathrm{m}$, 99.8 \% purity, Nihon New Metals Co. Ltd., Japan) and SWCNTs with diameter of $1.2 \mathrm{~nm}$ (I have synthesized by Laser ablation at IFW-TU-Dresden-Germany in 2002) were used as the raw materials were used as starting materials. The mixture containing $\left(\mathbf{M o}_{2} \mathbf{C}\right)_{1_{-} x}-(\mathbf{T i C})_{x}$ $(2 \leq x \leq 4)$ and with addition of 1 Wt $\%$ SWCNTs, (NCMC's) were prepared by wet milling in anhydrous alcohol for $\mathbf{3} \mathbf{h}$..

To obtain homogenized and fine powder mixtures, the powder mixtures of $\mathbf{M o}_{2} \mathbf{C}-\mathbf{T i C}$ were ball-milled at a high speed of 200 RPM for $\mathbf{1 2} \mathrm{h}$ by using WC balls (diameter: $\mathbf{3} \mathbf{~ m m}$ ) and ethanol as the milling media.
Preliminary treatment of SWCNTs was carried out to minimize the agglomerate of the added SWCNTs. Firstly; the weighed SWCNTs were immersed into acetone for about $20 \mathbf{h}$, and then were ultrasonically dispersed for $\mathbf{3} \mathbf{h}$.

Secondly, the treated SWCNTs (3 vol.\%) were mixed with the former ball-milled blend $\left(\mathbf{M o}_{2} \mathbf{C}-\mathbf{T i C}\right)$ by magnetic agitation for $\mathbf{8} \mathbf{h}$. Again, a ball milling was applied to the slurry $\left(\mathrm{Mo}_{2} \mathrm{C}-\mathrm{TiC} / \mathbf{1} \mathrm{Wt} \%\right.$ SWCNTs $)$ at a speed of 200 RPM for $10 \mathrm{~h}$ for further mixing.

Finally, the powder mixtures with dispersed SWCNTs were dried by rotary evaporator under vacuum condition and were sieved to 60 meshes.

Based on previous sintering tests, the composition ratio of the composites was designed as follows (vol.\%):

$\left(\mathrm{Mo}_{2} \mathrm{C}\right)_{1 \_\mathrm{x}}-(\mathrm{TiC})_{\mathrm{x}}(2 \leq \mathrm{x} \leq 4) / 1 \mathrm{Wt} \%$ SWCNTs (here after, it is referred as MTC).

The (NCMC's) were sintered by $\boldsymbol{S P S}$ methods (Fig.1). The tree sintering schedules are shown. In the spark plasma sintering process, temperature profile and punish displacement or shrinkage the displacement velocity is not presented here (Figure.1b).

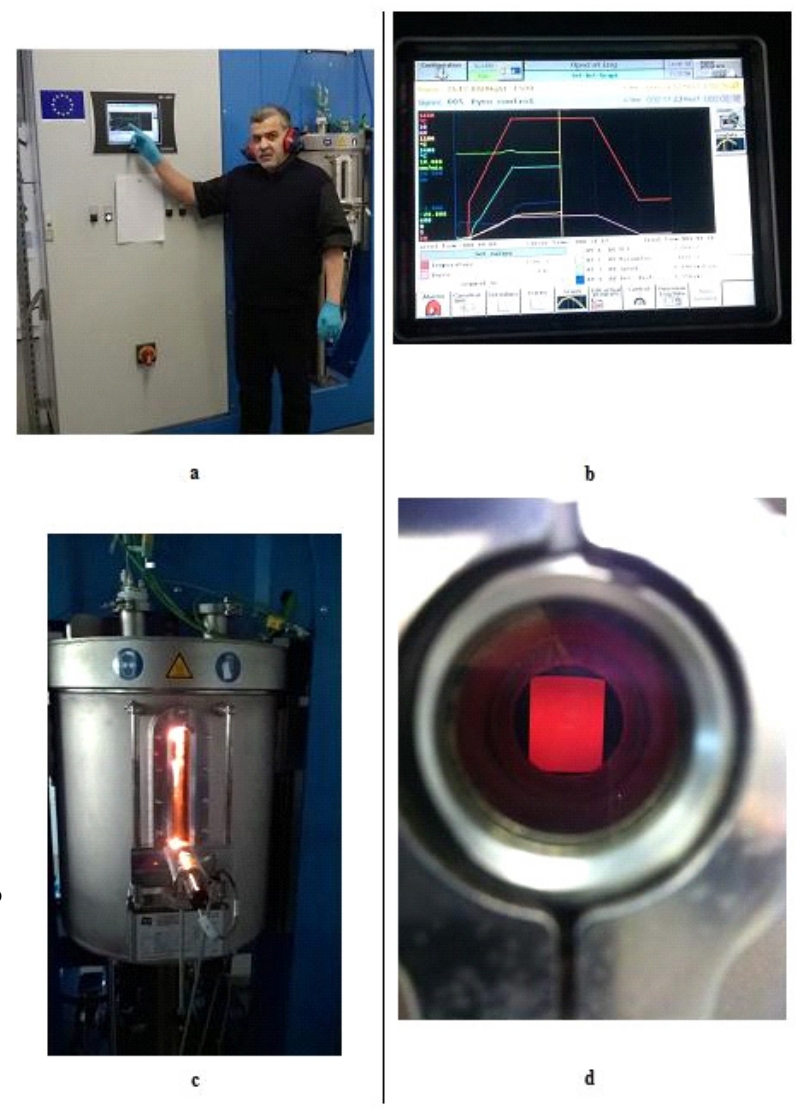

Figure 1. SINTER-LAB, FCT-HP D 25, SPS-1050, ENSICAEN. (a)-The author, (b)-Variation of the displacement, the displacement rate and the temperature in dependence of the heating time, $(\mathbf{c}, \mathbf{d})$ - The plasma produced by the current in the $\boldsymbol{S P S}$ chamber.

The resulting MTC ultrafine powder mixtures were hot-pressed in graphite dies (inner diameter: $20 \mathrm{~mm}$ ) coated with graphite lubricant at $\left(\mathbf{1 7 0 0 - 1 8 0 0}^{\circ} \mathbf{C}\right)$ in vacuum. 
The applied pressure of $70 \mathrm{MPa}$ was adjusted to the powder at room temperature and kept constant throughout the hot pressing process. The pressure was applied at the beginning of the sintering process because high green density is favorable for better densification rate by reducing the pores prior to the densification during heating. The heating rate was about $10{ }^{\circ} \mathrm{C} / \mathbf{m i n}$ and the dwelling time at terminal temperature was $\mathbf{6 0} \mathbf{~ m i n}$. The temperature was measured by an infrared pyrometer through a hole opened in the graphite die. Furthermore, for monitoring densification process, the shrinkage of the powder compact was measured by a displacement sensor during the hot pressing.

The dimensions of the finally hot pressed samples were about $\mathbf{2 0} \mathbf{~ m m}$ in diameter and $\mathbf{3} \mathbf{~ m m}$ in thickness.

The mixtures were loosely compacted into a graphite die of $20 \mathrm{~mm}$ in diameter after calculation of the weight according to the theoretical density of the compounds and sintered in the vacuum $(\mathbf{1} \mathbf{~ P a})$ at various temperatures (1700-1800 ${ }^{\circ} \mathrm{C}$ ) using an $S P S$ apparatus (Lab. SINTER, SPS-1050, Sumitomo Coal Mining Co. Ltd., GERMANY) (Table 1). A constant heating rate of $100^{\circ} \mathbf{C} / \mathbf{m i n}$ was employed, while the applied pressure was $70 \mathrm{MPa}$. The on/off time ratio of the pulsed current was set to $12 / 2$ in each run. The maximum current reached approximately $\mathbf{3 0 0 0} \mathrm{A}$ during sintering.

The soaking time at high temperatures was within 10 $\min$. The upper ram of the $\boldsymbol{S P S}$ apparatus was fixed, while the displacement of the shifting lower press ram was recorded in order to analyze the synthesis and sintering. The sintered samples are presented in the Fig.2.

Density of the sintered samples was measured by the Archimede's using the densimeter type Micromiritics Accupyc 1330. The microhardness at the top was measured by a diamond Vickers hardness tester (MVK-H1, Meter-Mitutoyo, Japan).

The indentation loads, ranging from 10 to $500 \mathrm{~N}$, were applied for $15 \mathrm{~s}$ for each measurement. The fracture toughness was measured using the Vickers indentation by the measurement of the producing failler.

In this study, $\mathbf{0 4}$ samples for each sintering process were fabricated to obtain an average relative density and hardness.

Young's modulus of the composites was determined by ultrasonic wave transition method measuring the velocity of ultrasonic sound waves passing through the material using an ultrasonic flaw detector (Panametrics Epoch III). The hardness and the fracture toughness were determined by the Vickers indentation method applying load of $294 \mathbf{~ N}$ $\left(\mathrm{HV}_{30}\right)$ and $490 \mathrm{~N}\left(\mathrm{HV}_{50}\right)$, by a Future Tech FLC-50VX hardness tester. For each sample 4 indentations were made and the stress intensity factor $\mathbf{K}_{\mathrm{IC}}$ was calculated from the length of Palmqvist cracks which developed during a Vickers indentation test using E. Rocha-Rangel's equation [39]:. The wear resistance and the friction coefficient will be performed in the near future. The hardness $(\mathbf{H})$, the elastic modulus $(\mathbf{E})$ and the fracture toughness $\left(\mathbf{K}_{\mathbf{I C}}\right)$ of the fabricated samples were measured under ambient conditions using the instrumented Vickers indentation method (Zwick Roell, ZHU 2.5 apparatus).

The impression diagonal (2a) was measured, and the hardness values were calculated according to the following relation:

$$
H_{v}=(1.8544 * F) /(2 a)^{2}
$$

the fracture toughness was also calculated by indentation fracture (IF) method according to the equation:

$$
K_{I C}=\left(0.16 H_{v} a^{1 / 2}\right)(c / a)^{-3 / 2}
$$

Where $\mathbf{H}_{\mathbf{v}}$ was the Vickers hardness, a was the half-length of the indentation diagonal and $\mathbf{c}$ was the half-length of the median crack generated by indentation. Generally, the fracture toughness measured by IF method were fluctuating values with relatively large deviations due to the phase distribution and measurements errors of calculation. Thus a linear regression model was applied to get a reliable value of indentation fracture toughness.

\begin{tabular}{|c|c|c|c|c|c|c|c|c|}
\hline Sintered Samples & $\mathbf{T}(\mathbf{C})$ & $\begin{array}{l}\text { Time of the } \\
\text { cycle(mn) }\end{array}$ & $\begin{array}{l}\text { Heating rate } \\
\text { (C/min) }\end{array}$ & $\mathbf{P}(\mathbf{M P a})$ & $\begin{array}{c}\text { Ar } \\
(\mathrm{Sccm})\end{array}$ & $\begin{array}{c}\begin{array}{c}\text { SWCNTs } \\
\text { d=1nm }\end{array} \\
\text {. }\end{array}$ & $\begin{array}{l}\text { Current } \\
\text { (A) }\end{array}$ & $\begin{array}{c}\text { Diameter of } \\
\text { Die (mm) }\end{array}$ \\
\hline TiC & 1700 & 10 & 100 & 70 & 200 & 00 & 3000 & 20 \\
\hline $\mathbf{M}_{0.6} \mathbf{T}_{0.4}$ & 1700 & 10 & 100 & 70 & 200 & 00 & 3000 & 20 \\
\hline $\begin{array}{c}M_{0.8} T_{0.2} / \\
1 W t \% \text { SWCNTs }\end{array}$ & 1700 & 10 & 100 & 70 & 200 & 1.0 & 3000 & 20 \\
\hline
\end{tabular}

Table 1. SPS synthesis parameters

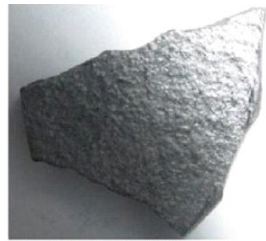

(a)

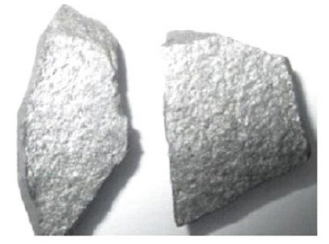

(b)

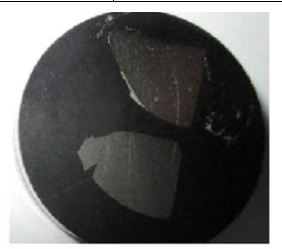

(c)

\section{$4 \mathrm{~mm}$}

Figure 2. Images of sintered MTC: (a, b) coarse grinding; (c) fine polishing. 
To obtain the values of $\mathrm{A}, \mathrm{B}$ and $\mathrm{R}^{2}$, a series of indentation loads $(10 \mathrm{~N}, 50 \mathrm{~N}, 100 \mathrm{~N}, 300,500 \mathrm{~N})$ were applied to get the relations of $\mathbf{P}$ and $\mathbf{c}^{3 / 2}$.

\section{Results and Discussion}

\subsection{XRD Analysis of Sintered $M_{1-x} T_{x}(2 \leq x \leq 4) / 1 W t \%$ SWCNTs, (NCMC's)}

XRD analysis of the samples indicates that the only phases formed in the sample without SWCNTs are titanium carbide TiC, with a cubic crystal structure and $\mathbf{M o}_{2} \mathbf{C}$ with orthorhombic crystal structure. The addition of $\mathbf{1 W t} \%$ SWCNTs reinfort has considerable effect on XRD pattern. XRD spectrum of the (NCMC's), which indicates that the reaction between the TiC powders and SWCNTs did happen during the sintering process. It is considered that disordered carbons on wall defects and the open ends of the SWCNTs serve as carbon sources for interfacial reaction. The sintered samples consisted mainly $\mathbf{M o}_{2} \mathbf{C}-\mathbf{T i C}$ of matrix, as major phases, and some secondary phases, such as SWCNTs appeared depending on the sintering temperature. X-ray diffraction patterns of sample $M_{1-x} T_{x}(2 \leq x \leq 4) \quad / 1 W t \% \quad$ SWCNTs, $\quad M_{0.8} T_{0.2} / 1 W t \%$ SWCNTs, (NCMC's) sintered at 70 MPa pressure were enhanced because they are reinforced with the SWCNTs phases, TiC and SWCNTs with higher intensity, the SWCNTs content at the sintering temperature of $1700{ }^{\circ} \mathrm{C}$ for $10 \mathrm{~min}$ at $70 \mathrm{MPa}$, which was reduced to $10 \%$ when sintered at pressure because it reacted with $\mathbf{T i C}$ to produce TiC-SWCNTs in the TiC grain new intergranular reinforcement slightly increased.

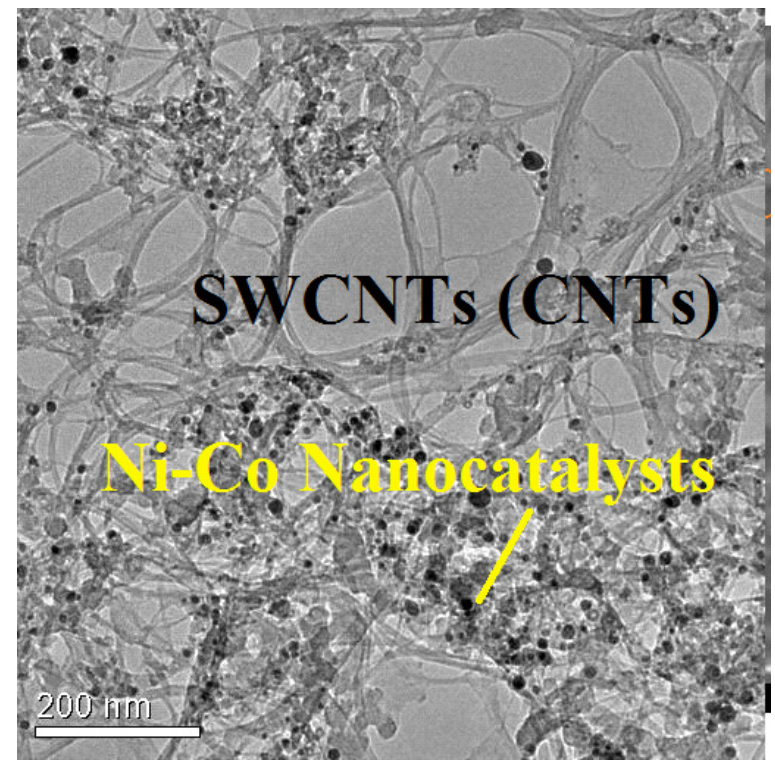

These results suggest that $\mathbf{T i C}$ grains grew preferentially with the basal planes rotating towards the loading direction of SWCNTs.

\subsection{SEM Microstructural Observation of Sintered $M_{1-x} T_{x}(2 \leq x \leq 4) / 1 W t \%$ SWCNTs, (NCMC's)}

The SEM microstructures of samples with following compositions:

$M_{1-x} T_{x} \quad(2 \leq x \leq 4) \quad / 1 w t \% \quad$ SWCNTs, $\quad M_{0.8} T_{0.2} / 1 W t \%$ SWCNTs, with $x=0.2$

\section{$\mathrm{T}$ (TiC)}

$M_{1-x} T_{x}(2 \leq x \leq 4) / 1 W t \%$ SWCNTs, $M_{0.6} T_{0.4}$, with $x=0.4$

The SEM microstructures (Fig. 3) revealed that the nanocomposite has good density of the binderless phases in the final structure of the products. The high magnification representative microstructure of the sample without SWCNTs consists of large $\mathbf{M o}_{2} \mathbf{C}$ (dark) grains and $\mathbf{T i C}$ (gray) particle sintered together (Fig. 3c-d-e-f-h). The addition of $1 \mathbf{~ W t} \%$ SWCNTs (Fig.3e-f) to the reaction changed the morphology of TiC from slightly finer grains with near spherical morphology to the large plate like grains. Fig.3e-d, showed the SWCNTs into TiC particle grain and no in the grain boundaries forming the interface with different orientations. The mechanical properties are induced by both phases and grain boundaries. This is a contribution to the increasing of the microhardness. These steps are characteristics of crystal growth with interface-controlled growth mechanism [41]. In the Fig. $3 g$ is presented the typical of the loss of SWCNTs identified by the pore like structure (holes) in addition to unreacted SWCNTs.

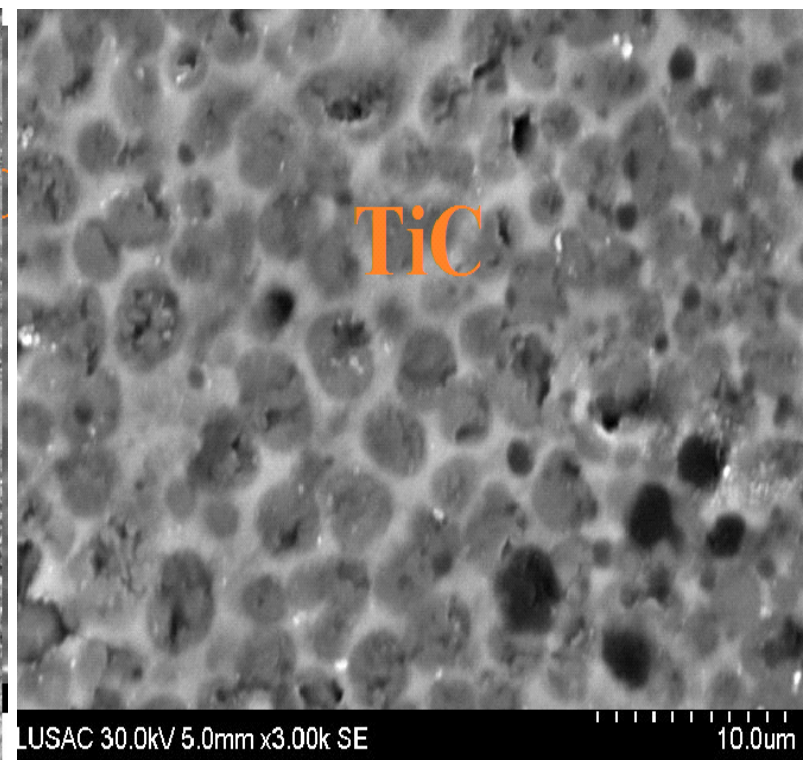

b 


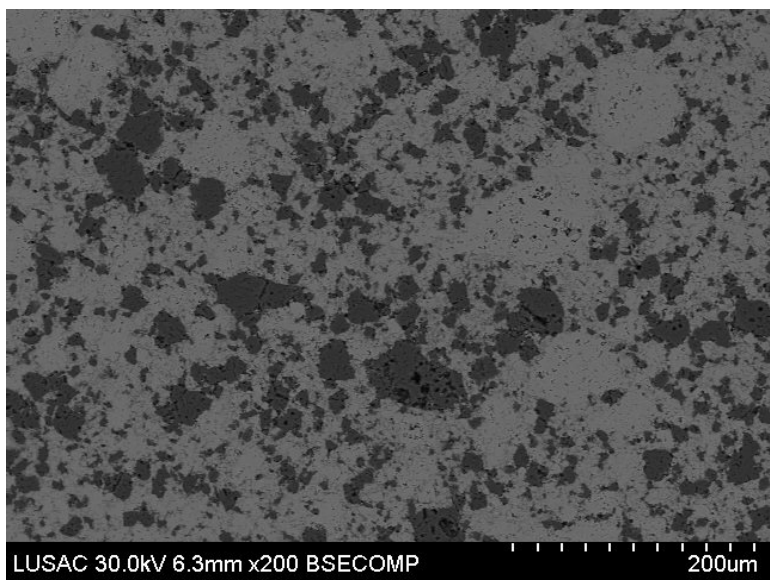

c
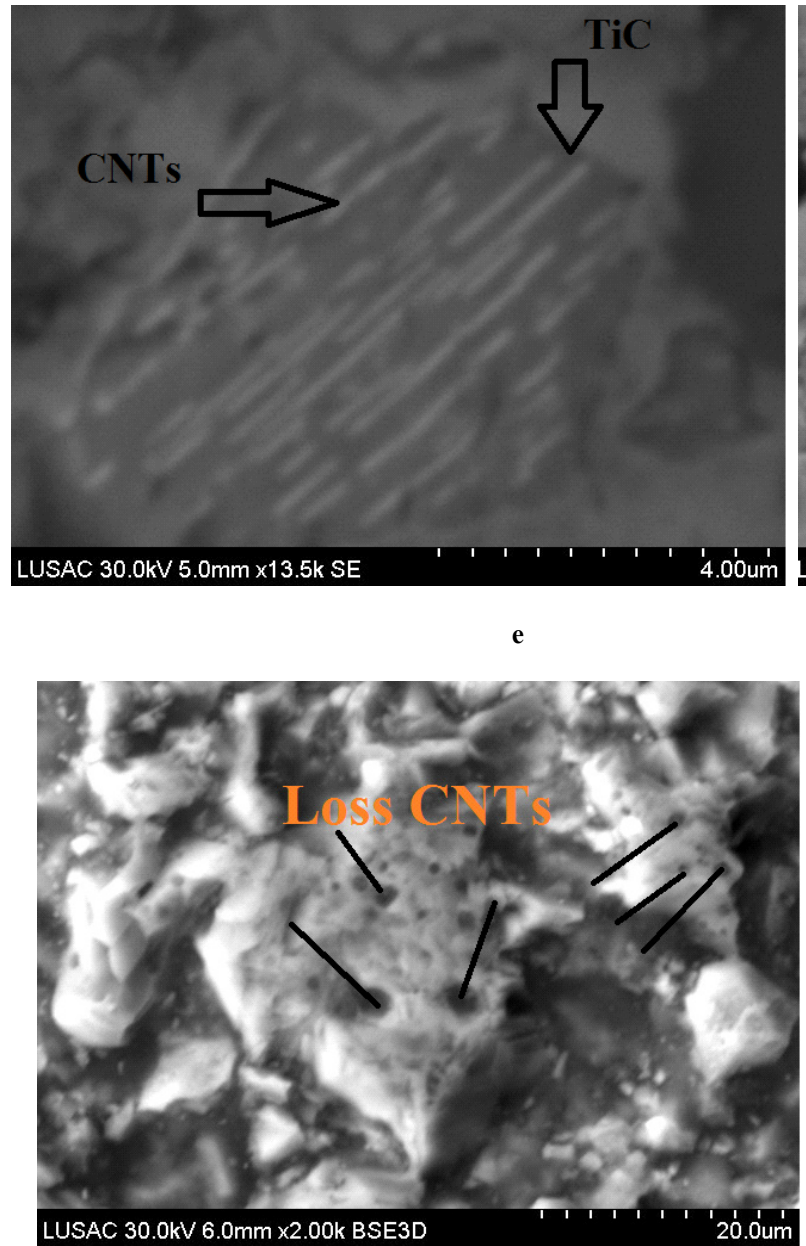

g

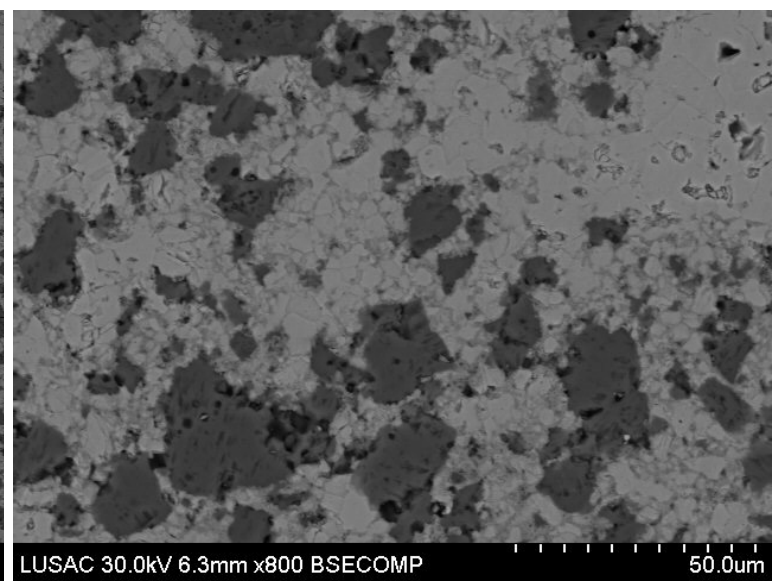

d

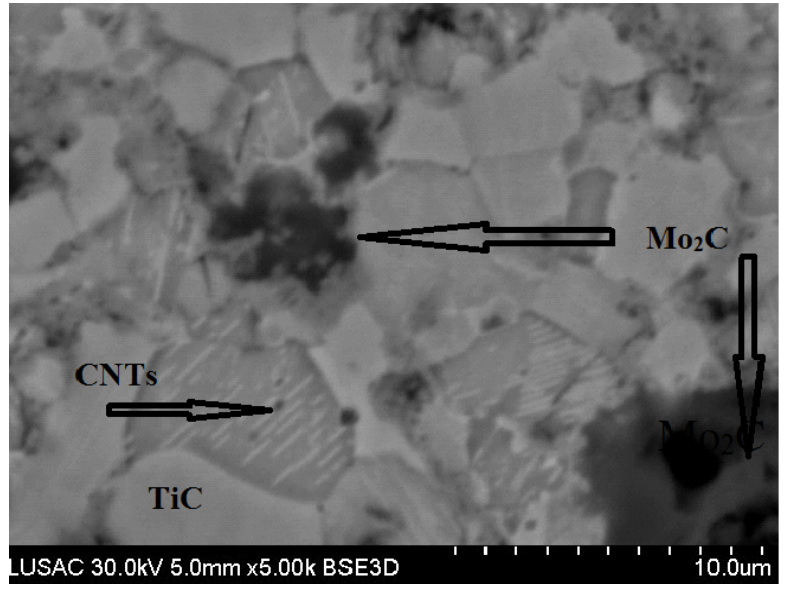

f

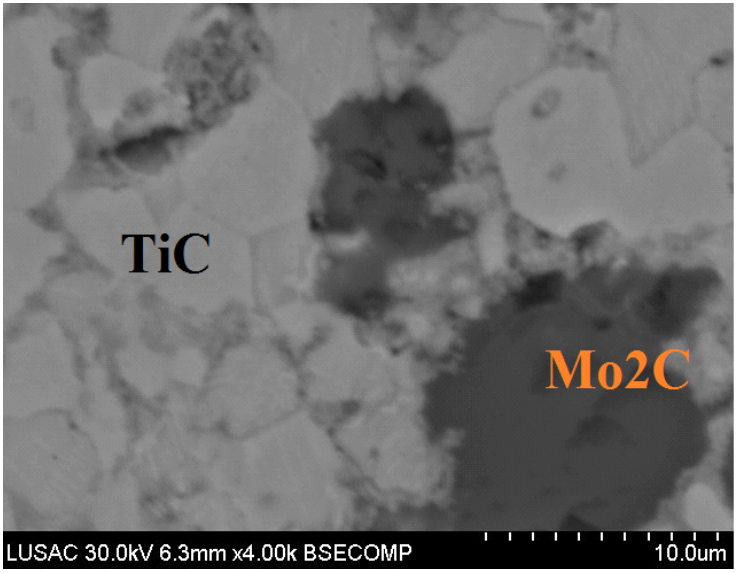

h

Figure 3. High magnification microstructural representative SEM image of MTC polished and etched surface for the sintered samples using a 20-mm diameter die. (a)-TEM of SWCNTs, (b)-Sintered TiC grains, (c)-Nanocomposites overview, (d)- nanocomposites overview with magnification, (e)-SWCNTs into the TiC grain, (f)-SWCNTs into the TiC grains ,( g)-Pore like structure of losses SWCNTs , (h)-Nanocomposites overview with higher magnification.

High magnification images of the starting ultrafine powder of SWCNTs and sintered titanium carbide (TiC) are presented in Figure.3a-b.

In the Figure 4, the microstructural representation and EDS analysis displays elemental analyses of the various regions of the sintered samples. Secondary electron image, atomic concentration cartographies of $\mathbf{M o}, \mathbf{T i}$, and $\mathbf{C}$. 

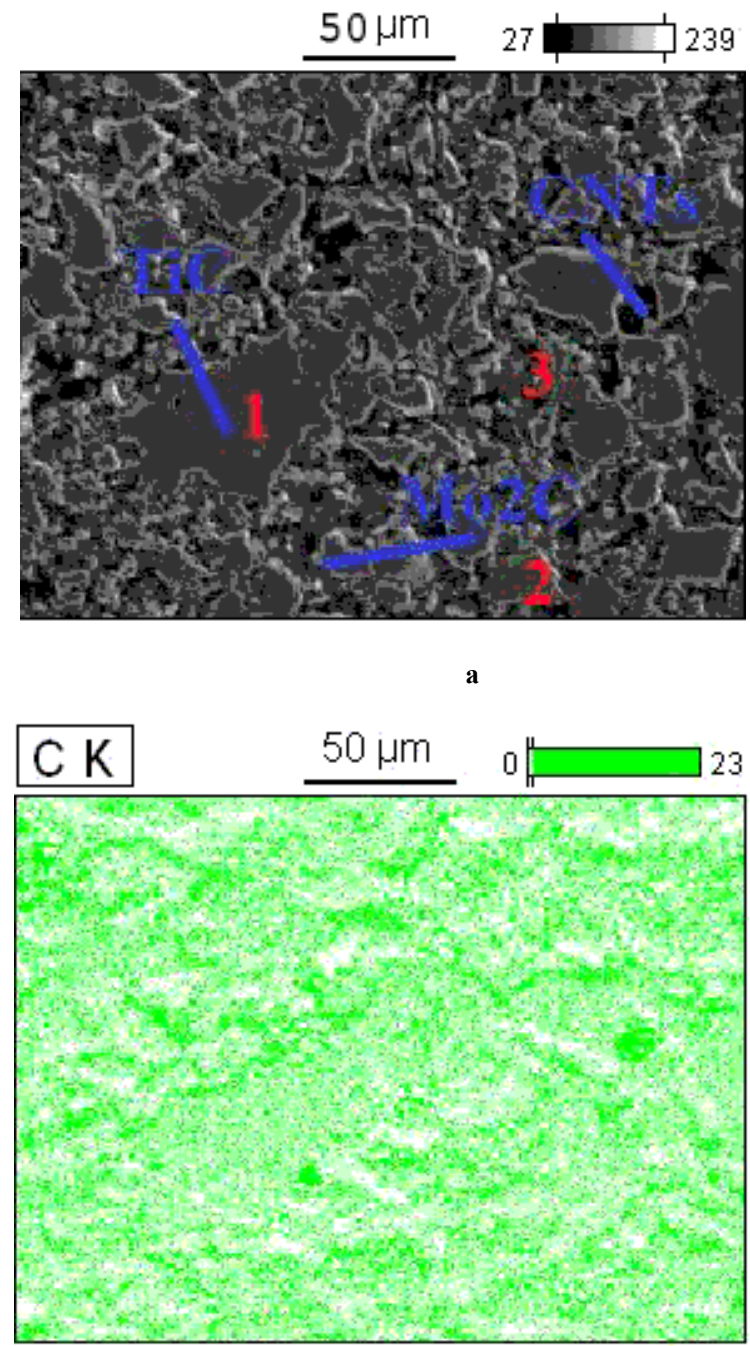

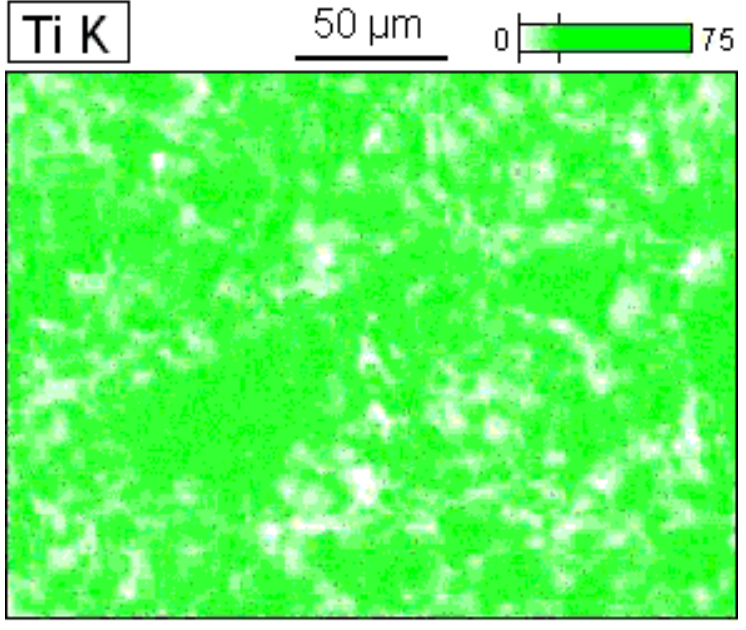

b

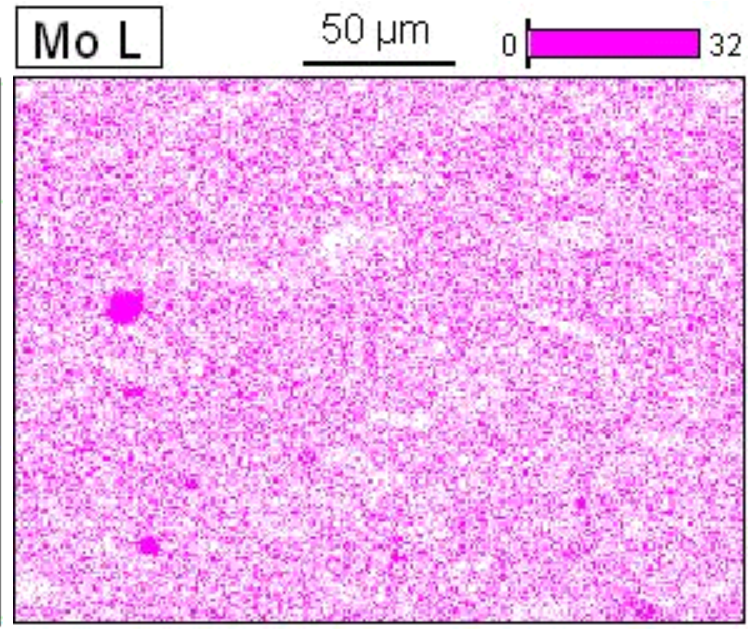

d

Figure 4. Microstructural representation and EDS maps of MTC analysis displays elemental analyses of the various regions of the sintered samples. Secondary electron image, atomic concentration cartographies of $\mathbf{M o}, \mathbf{T i}$, and $\mathbf{C}$ of $\mathbf{M T C}$ polished and etched surface for the sintered samples using a 20-mm diameter die. :(a)- Overview of the nanocomposite , (b)- Cartographies of Ti , (c)- Cartographies of C, (d)- Cartographies of Mo.

EDS spectra and was used to determine the elemental composition of the different regions in the sample and are presented at the Figure 5. 


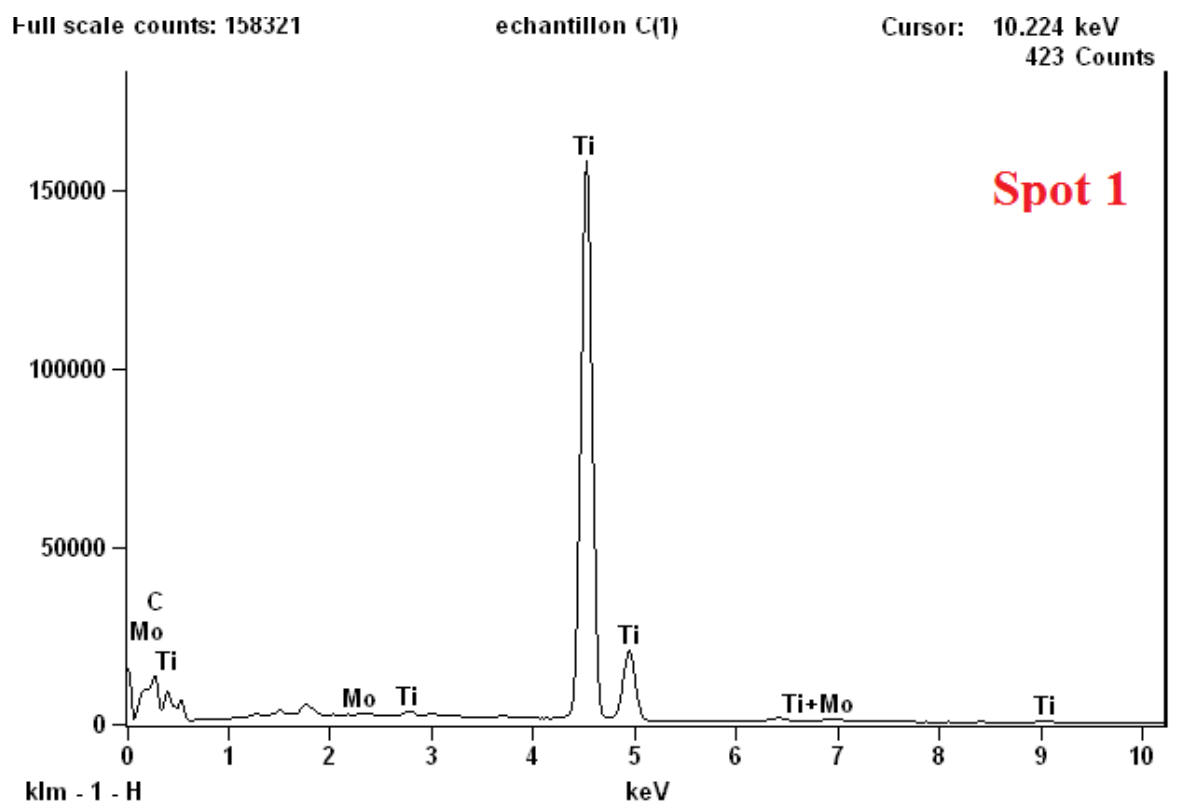

Full scale counts: $57552 \quad$ echantillon C(1)
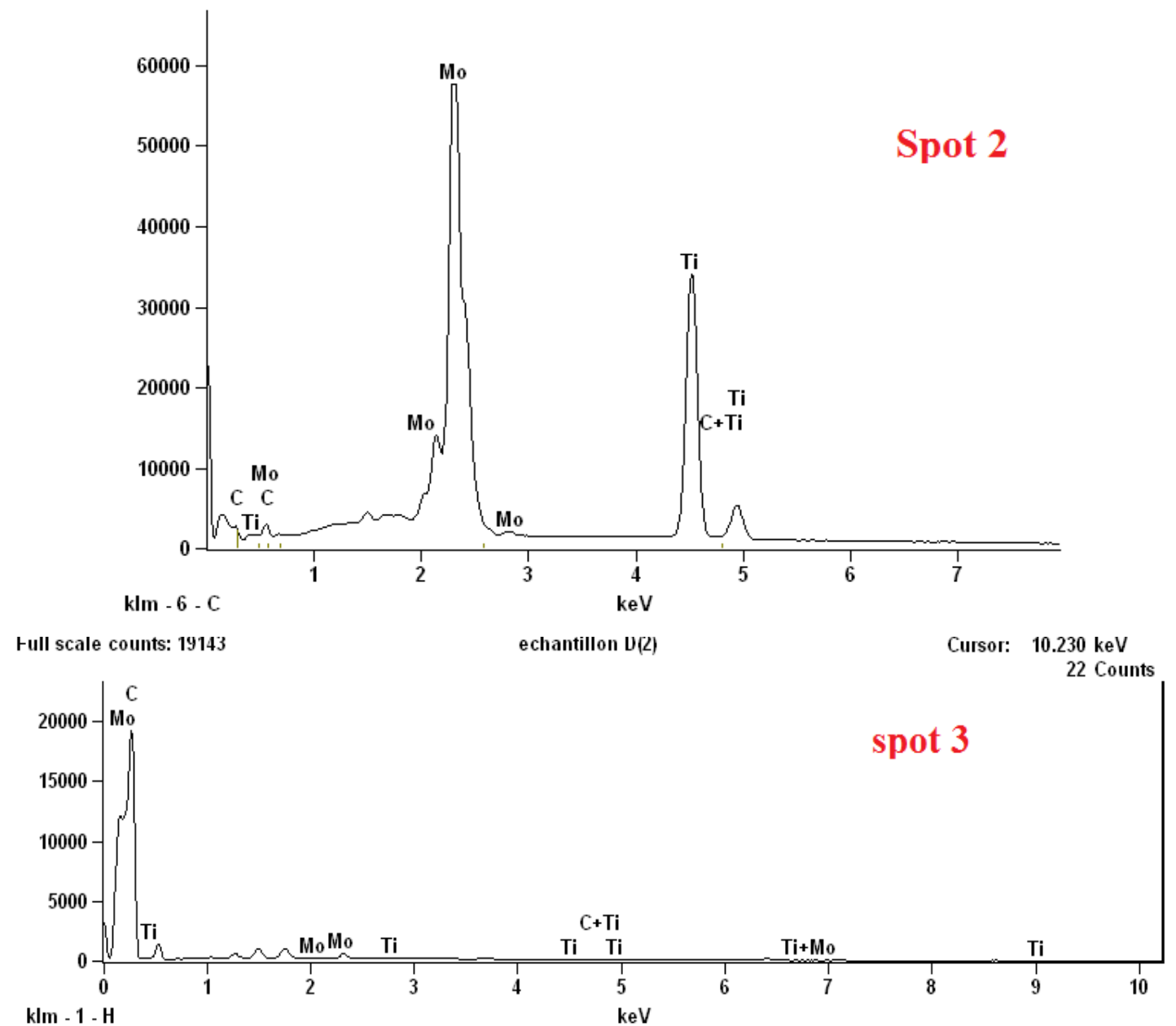

Figure 5. EDX spectra in different regions of MTC polished and etched surface for the sintered samples using a 20-mm diameter die: (Spot $)_{1}$ - TiC regions, $\left(\mathrm{Spot}_{2}\right)-\mathbf{M o}_{2} \mathbf{C}$ regions, $\left(\mathrm{Spot}_{3}\right)-\mathbf{S W C N T s}$ regions 


\subsection{Relative Density of the Sintered $M_{1-x} T_{x}(2 \leq x \leq 4) /$ 1Wt\% SWCNTs, (NCMC's)}

The variation of the relatives density of sintered $M_{1-x} T_{x}(2 \leq x \leq 4) \quad / 1 W t \% \quad$ SWCNTs, (NCMC's) with SWCNTs reinforcement is shown in Table.2. The theoretical density of the composite used for obtaining relative density was calculated using a rule of mixture, using the densities of two constituent phase ( $\rho_{\mathrm{M}_{02} \mathrm{C}=} \mathbf{4 . 5 3}$ $\left.\mathrm{g} / \mathrm{cm}^{2}, \rho_{\text {TiiC }}=4.50 \mathrm{~g} / \mathrm{cm}^{2}, \rho_{\text {SwCNTs }}=2.25 \mathrm{~g} / \mathrm{cm}^{2}\right)$ with the given $\boldsymbol{S P S}$ processing parameters, the $\mathbf{M}_{\mathbf{1 - \mathrm { x }}} \mathbf{T}_{\mathbf{x} / /} / \mathbf{1 W t} \%$ SWCNTs with $\mathbf{x}=\mathbf{2}$, sample exhibited best densification with relative density greater than $\mathbf{9 9 . 5 \%}$, with the similar processing parameters with variation of TiC/SWCNTs content. The relative density increased with increasing of the reinforcement of $\mathbf{1 . 0} \mathbf{w t} \%$ SWCNTs. The $\mathrm{M}_{0.8} \mathbf{T}_{\mathbf{0 . 2}} / \mathbf{1 W t} \%$ SWCNTs, (NCMC's) at $\mathrm{T}=\mathbf{1 7 0 0}^{\circ} \mathrm{C}$ exhibited relative density of about $\mathbf{9 9 . 5 \%}$.

Table 2. Basic physical-mechanical properties of the samples obtained by SPS sintering

\begin{tabular}{|c|c|c|c|}
\hline Sintered samples & $\mathbf{T i C}$ & $\mathbf{M}_{\mathbf{0 . 6}} \mathbf{T}_{\mathbf{0 . 4}}$ & $\begin{array}{c}\mathbf{M}_{\mathbf{0 . 8}} \mathbf{T}_{0.2} / \mathbf{1 W t} \% \\
\text { SWCNTs, }\end{array}$ \\
\hline $\begin{array}{c}\text { Density (relative density) } \\
\text { g/cm }\end{array}$ & $\mathbf{9 2 . 0 4}$ & $\mathbf{9 5 . 0 6}$ & $\mathbf{9 9 . 5}$ \\
\hline $\begin{array}{c}\text { Young's modulus } \\
\text { (relative Young's) } \\
\text { GPa (\%) }\end{array}$ & $\mathbf{4 3 9 . 4}$ & $\mathbf{4 9 0 . 6}$ & $\mathbf{5 2 0 . 8}$ \\
\hline
\end{tabular}

Depending on the final density to be achieved, the SPS operating condition were properly chosen, that is, $\mathbf{1 7 0 0}^{\circ} \mathrm{C}$, $70 \mathrm{Mpa}$ for $10 \mathrm{~min}$, to obtain a highest relative density for the (NCMC's), $\mathbf{M}_{\mathbf{0 . 8}} \mathbf{T}_{\mathbf{0 . 2}} / \mathbf{1 W t} \%$ SWCNTs, dense $\mathbf{M}_{\mathbf{0 . 6}} \mathbf{T}_{\mathbf{0 . 4}}$, TiC for zero compacts porosity, 99.5, 95.06, and 92.04, respectively.

The $0.5 \%$ porosity of the sample $\mathbf{M}_{\mathbf{0 . 8}} \mathbf{T}_{\mathbf{0 . 2}} / \mathbf{1 W t} \%$ SWCNTs exhibited a round microstructure with high ductility, $99.5 \%$.

Also, the easy sledding of their walls when attached by weak van der Waals force of coalesced MWCNTs can probably increases the relative density. The density of the sintered samples was determined using the Archimedes helium immersion method.

\subsection{Microhardness and Fracture Toughness $\left(K_{I C}\right)$ of the Sintered $M_{1-x} T_{x}(2 \leq x \leq 4) / 1 W t \%$ SWCNTs,(NCMC's)}

According to the above results, it can be concluded that the Vickers hardness has been improved by adding SWCNTs and enhanced with the fracture toughness value giving a better ductility for the reinforced SWCNTs samples.

Figure 6 shows the hardness as a function of the applied indentation load for the same sample. At lower loads, the microhardness reaches a low hardness a constant value of 33.6, 14.8 and 20.6 GPa for reinforced $\mathbf{M}_{0.8} T_{0.2} / 1 \mathrm{Wt} \%$ SWCNTs, unreinforced TiC, and $\mathbf{M}_{0.6} \mathbf{T}_{0.4}$, (NCMC's) respectively

In the present study, the high hardness of the SPS synthesized sample containing (NCMC's), $\mathbf{M}_{\mathbf{0 . 8}} \mathbf{T}_{\mathbf{0 . 2}} / \mathbf{1} \mathbf{W t} \%$ SWCNTs at $\mathbf{T}=1700{ }^{\circ} \mathrm{C}$ may be attributed to its high density $(\mathbf{9 9 . 5} \%$ from theoretical).

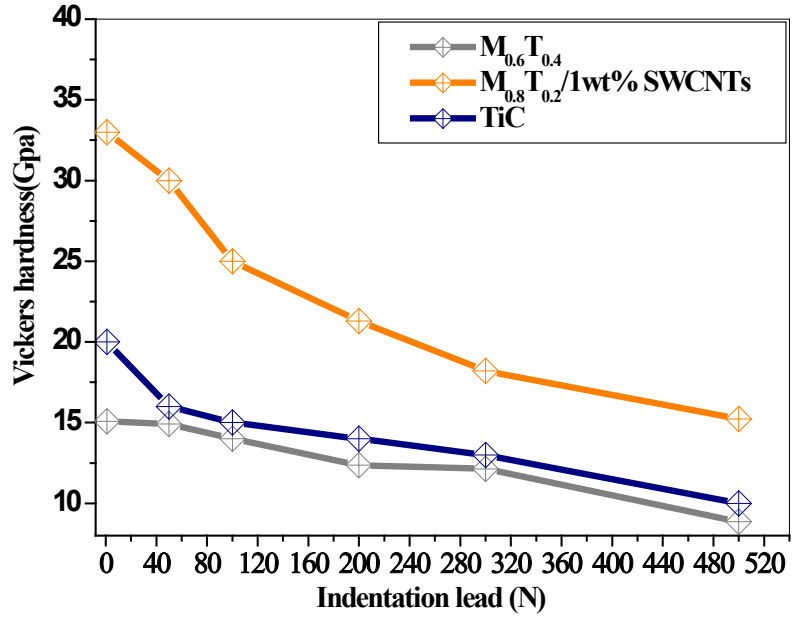

Figure 6. Representation the variation of Vickers microhardness function of the indentation lead of MTC polished and etched surface for the sintered samples using a $\mathbf{2 0} \mathbf{~ m m}$ diameter die

Figure 6 presents the variation of Vickers microhardness of $\mathbf{M}_{\mathbf{0 . 8}} \mathbf{T}_{\mathbf{0 . 2}} \mathbf{1} \mathbf{1 W t} \%$ SWCNTs, (NCMC's) with SWCNTs reinforcement content at $\mathbf{T}=\mathbf{1 7 0 0}^{\circ} \mathbf{C}$ with the indentation lead. The microhardness of the (NCMC's) increased almost linearly with SWCNTs reinforcement and with addition TiC (20 to 40 vol. \%) content in $\mathrm{Mo}_{2} \mathrm{C}$ hard carbide.

The hardness of SWCNTs (28-30 GPa) is nearly 2 times the previously reported values of hardness of $\mathrm{TiC}$ (15.8GPa). For the nearly single phase $\mathrm{Mo}_{2} \mathrm{C}$ (SPS) sintered in this investigation, the microhardness was found to be $5.94 \mathrm{GPa}$ (measured with indentation load of $\mathbf{1 0} \mathbf{~ N}$ ), which is higher than the previously reported hardness values for monolithic in the literature. While the higher hardness of the $\mathbf{M}_{\mathbf{0 . 8}} \mathbf{T}_{\mathbf{0 . 2}} / \mathbf{1 W t} \%$ SWCNTs sample could be due to a minor amount of SWCNTs intragranular reinforced $\mathbf{T i C}$ grain phase in the composite $\mathbf{M o}_{2} \mathrm{C}-\mathbf{T i C}$.

The microhardness in the range of about 2.5-3.5 GPa was found for lower loads $(\mathbf{1 0} \mathbf{N})$. A slight increase in average hardness has been obtained from (NCMC's) prepared by sintering $\mathbf{M}_{\mathbf{0 . 8}} \mathbf{T}_{\mathbf{0 . 2}} / \mathbf{1} \mathbf{W t} \%$ SWCNTs at $\mathbf{T}=\mathbf{1 7 0 0}^{\circ} \mathrm{C}$ exhibited highest hardness of about 33.6 GPa (Fig.6). It is considered that, $\mathbf{4 0} \mathbf{v o l \% ~} \mathbf{T i C}$ and the remaining SWCNTs act as reinforcements and plays the major role in the consolidation of the products.

The best product contained $\mathbf{M}_{\mathbf{0 . 8}} \mathbf{T}_{\mathbf{0 . 2}} / \mathbf{1 W t} \%$ SWCNTs which was sintered at $1700{ }^{\circ} \mathrm{C}, 70 \mathrm{MPa}$ for $10 \mathrm{~min}$. The hardness of the $\mathbf{M}_{0.8} \mathbf{T}_{\mathbf{0 . 2}} / \mathbf{1 W t} \%$ SWCNTs increases with increasing of TiC and SWCNTs content (Fig.6).

With this, the electro discharge among powders may lead to self-heating and purification of the particle surface, resulting in activation of the formation of the (NCMC's).

The corresponding SEM micrographs around the indentation marks at the top surfaces show the lateral cracks extension from the indentation mark (Fig. 7). 


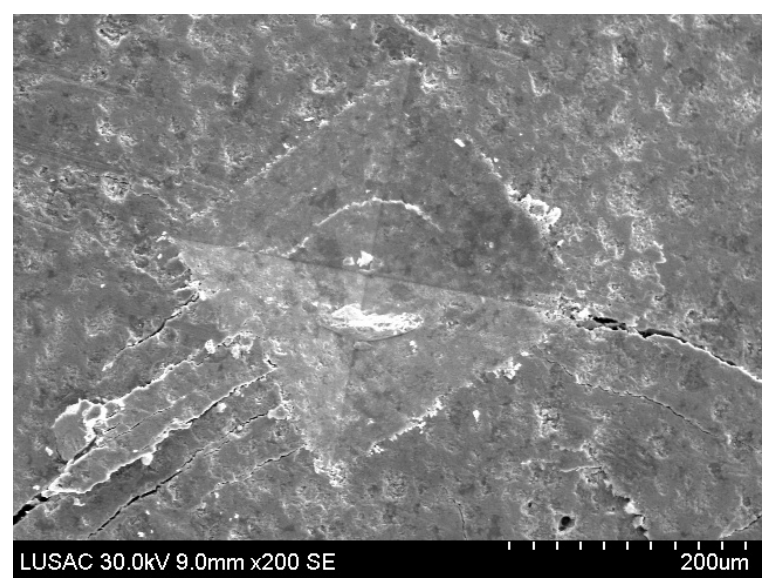

$\mathrm{a}$

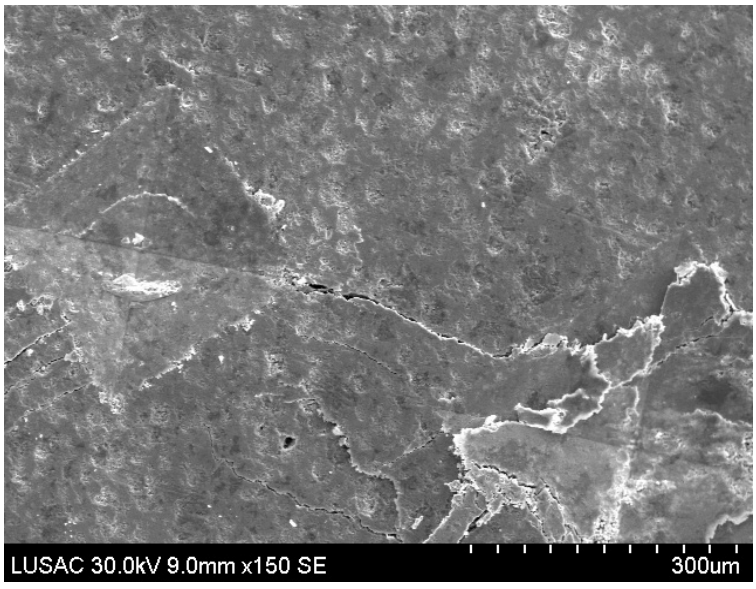

$\mathrm{c}$

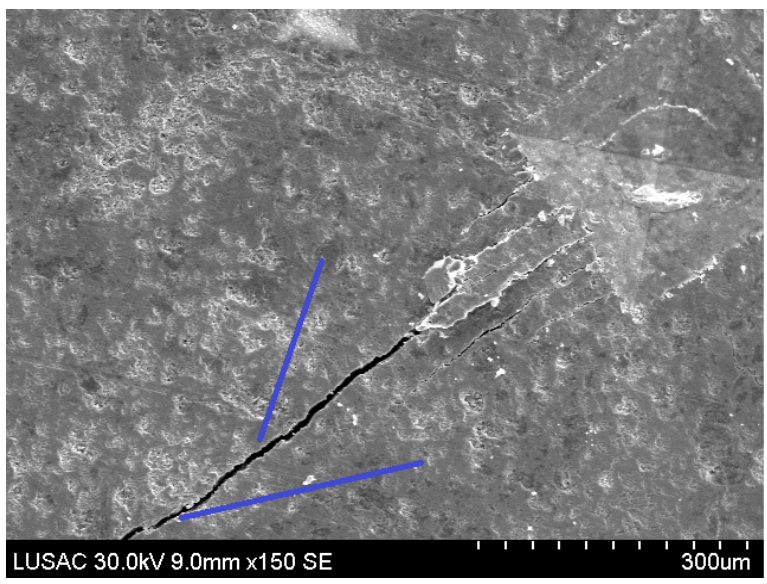

$\mathrm{b}$

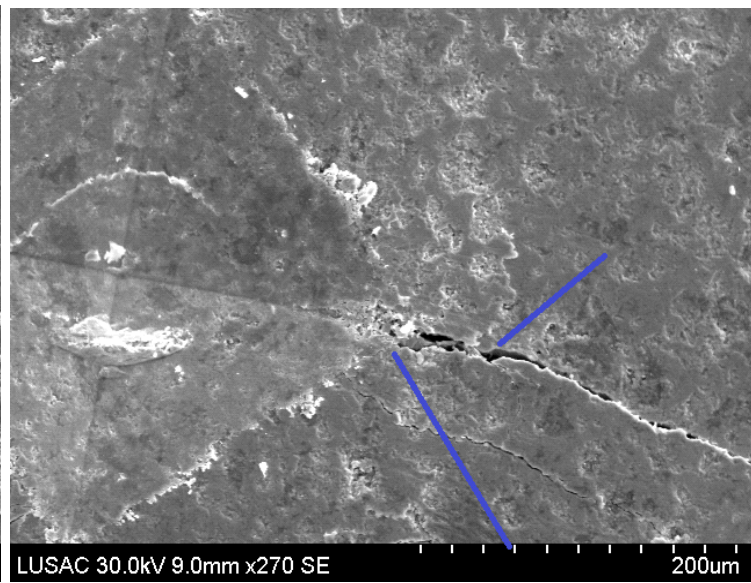

d

Figure 7. SEM, BSE micrograph of cracks at the corners of Vickers indents: of etched MTC showing a purely transgranular crack growth; and revealing an intergranular crack with deflection and crack bridging: (a)-Transgranular crack, (b) - Intergranular crack, (c) - Crack deflection, d- Crack bridging

The typical micrographs of the indentations were shown in the Fig. 8 . For each indentation load, at least $\mathbf{0 6}$ tests were carried to achieve the average indentation parameter $\mathbf{a}$ and $\mathbf{c}$.

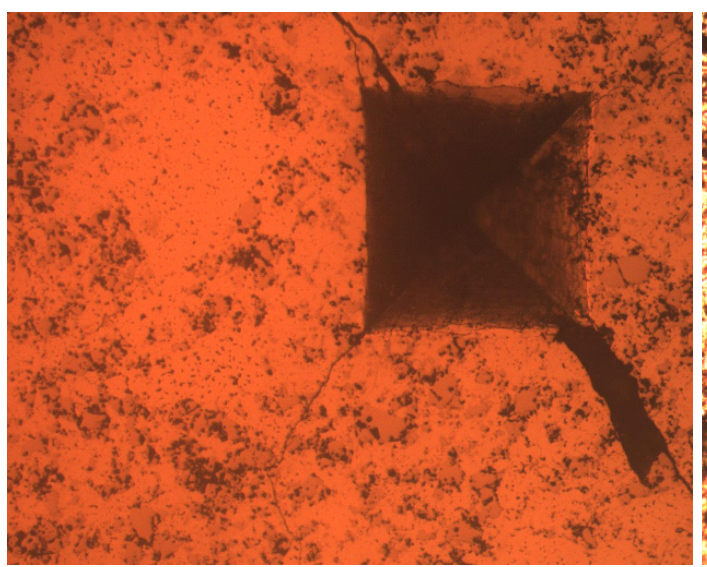

a

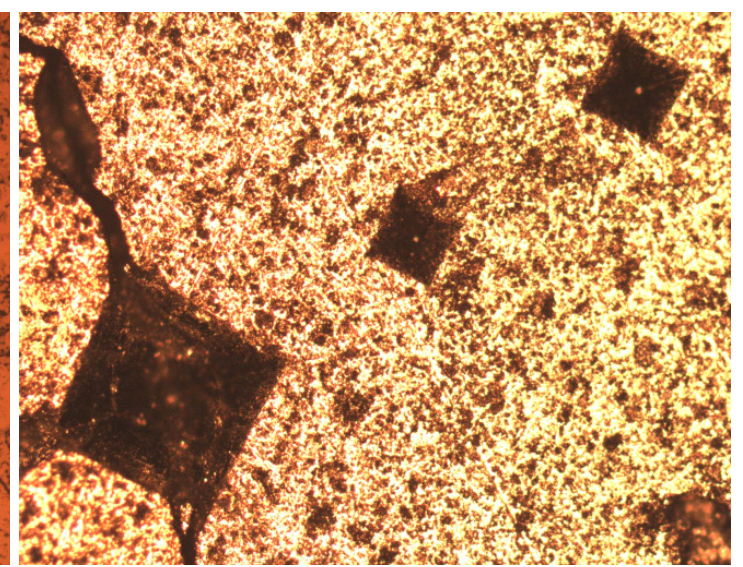

b 

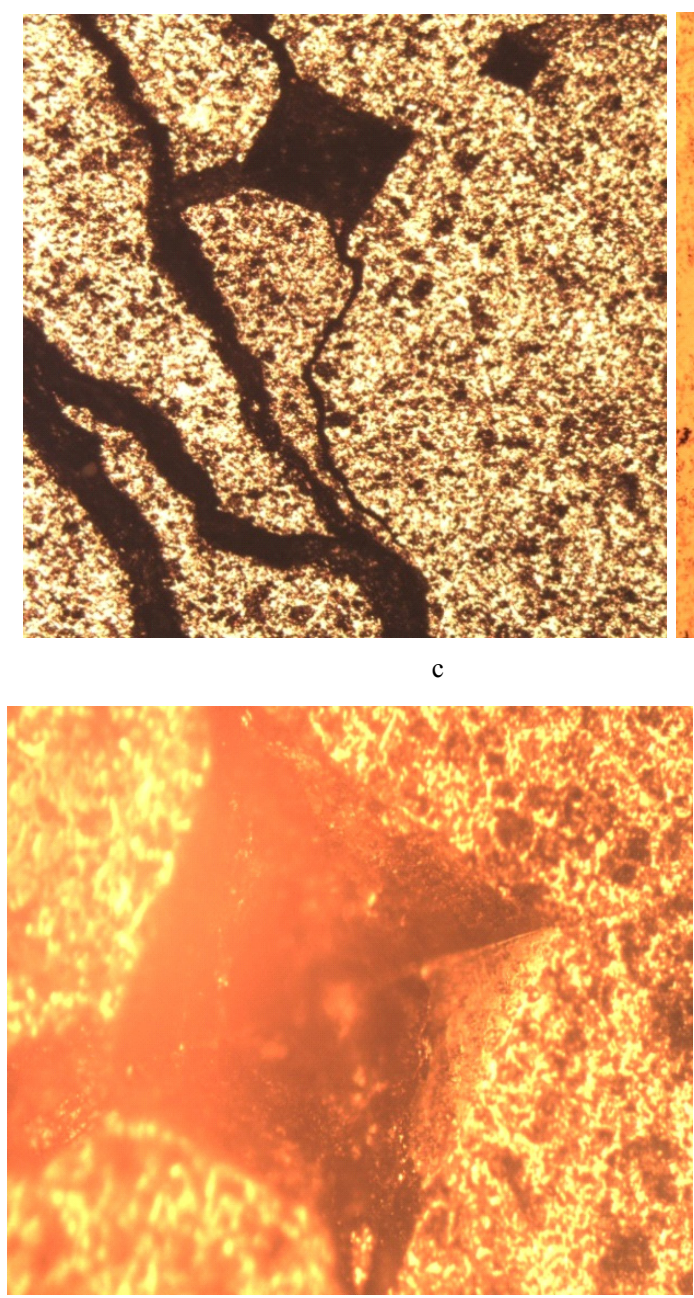

e

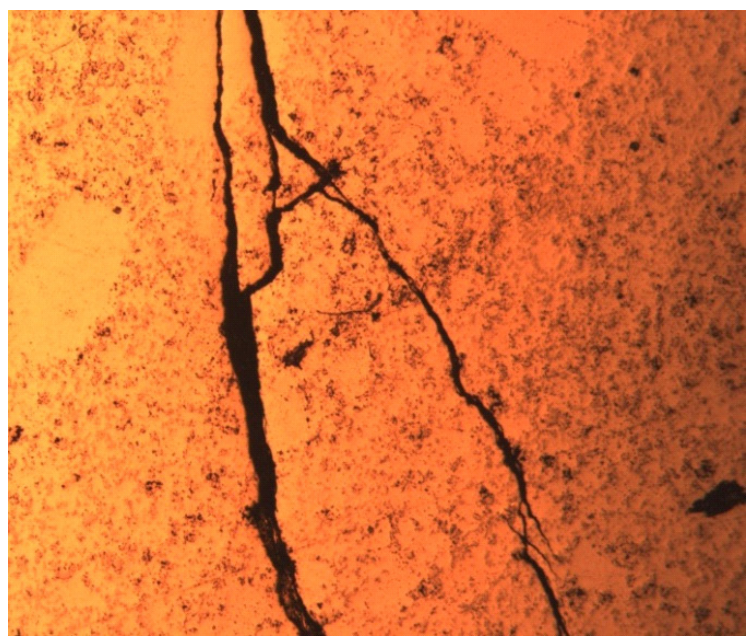

$\mathrm{d}$

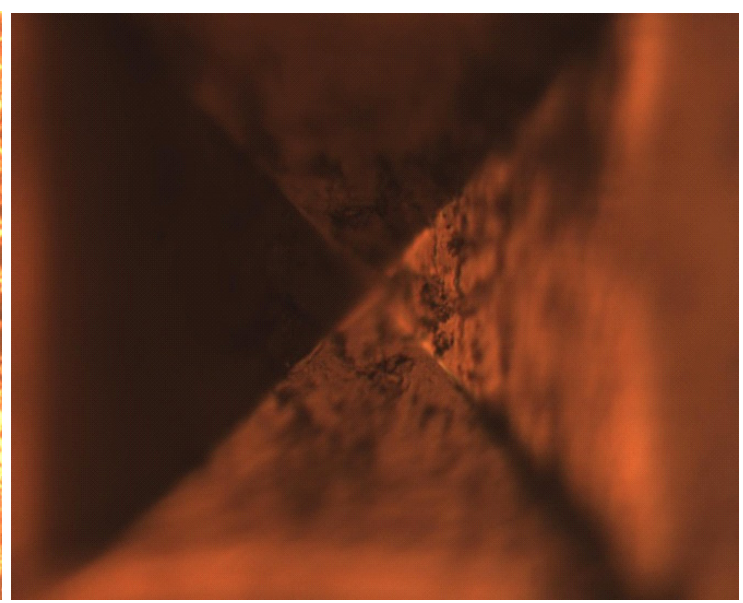

Figure 8. Optical micrograph of crack patterns used for IFT calculations of (a, b)-MTC tested at 300 N, (c)-MTC tested at 500 N. Micrographs of cracks at the corners of Vickers indentation: (d)-Etched MTC showing a purely transgranular crack growth and (e, f)-High magnification of indentation label.

The relevant data were listed in Table 3.In Figure. 9, a linear regression analysis was applied to the relations of $\mathbf{P}$ and $\mathbf{c}^{3 / 2}$ by the least square method.

Table 3. Data of Vickers indentation cracks and fracture toughness $\left(\mathbf{K}_{\mathbf{I C}}\right)$

\begin{tabular}{|c|c|c|c|c|c|c|}
\hline Sintred samples & $\begin{array}{l}\text { Half-length of } \\
\text { indentation diagonal } \\
\quad \mathbf{a}(\mu \mathrm{m})\end{array}$ & $\mathbf{l}_{(\mu \mathrm{m})}$ & $\begin{array}{l}\text { Half-length of } \\
\text { median crack } \\
\qquad \mathbf{c}(\mu \mathrm{m})\end{array}$ & $\begin{array}{c}\text { Indentation } \\
\text { parameter } \mathrm{c}^{3 / 2} \\
(\mu \mathrm{m})^{3 / 2}\end{array}$ & $\begin{array}{l}K_{I C} \\
(G p a \\
\left.\mathbf{m}^{1 / 2}\right)\end{array}$ & $\begin{array}{c}\text { HV } \\
\text { (GPa) }\end{array}$ \\
\hline $\begin{array}{c}\mathrm{TiC} \\
\mathrm{P}=\mathbf{5 0 0} \mathrm{N}, \mathrm{Hv}_{\mathbf{5 0}} \\
\mathrm{P}=\mathbf{3 0 0} \mathrm{N}, \mathbf{H v}_{\mathbf{3 0}}\end{array}$ & $\begin{array}{l}132.2 \\
148.3\end{array}$ & $\begin{array}{l}367.8 \\
400.3\end{array}$ & $\begin{array}{c}500 \\
352.3\end{array}$ & $\begin{array}{c}11180 \\
6604\end{array}$ & $\begin{array}{l}6.75 \\
6.75\end{array}$ & $\begin{array}{l}10.3 \\
13.2\end{array}$ \\
\hline $\begin{array}{c}M_{0.6} T_{0.4} \\
P=500 \mathrm{~N}, \mathrm{Hv}_{50} \\
\mathrm{P}=\mathbf{3 0 0} \mathrm{N}, \mathrm{Hv}_{\mathbf{3 0}}\end{array}$ & $\begin{array}{l}110.1 \\
101.5\end{array}$ & $\begin{array}{l}247 \\
282\end{array}$ & $\begin{array}{l}491 \\
387\end{array}$ & $\begin{array}{c}10879 \\
7613\end{array}$ & $\begin{array}{l}4.26 \\
4.26\end{array}$ & $\begin{array}{c}5.6 \\
12.5\end{array}$ \\
\hline $\begin{array}{c}\mathrm{M}_{0.8} \mathrm{~T}_{0.2} / \mathbf{1 W t} \% \\
\text { SWCNTs } \\
\mathrm{P}=\mathbf{5 0 0} \mathrm{N}, \mathrm{Hv}_{\mathbf{5 0}} \\
\mathrm{P}=\mathbf{3 0 0} \mathrm{N}, \mathrm{Hv}_{\mathbf{3 0}}\end{array}$ & $\begin{array}{l}90.2 \\
85.3\end{array}$ & $\begin{array}{l}667.7 \\
460.3\end{array}$ & $\begin{array}{l}757.9 \\
545.6\end{array}$ & $\begin{array}{l}20827 \\
12723\end{array}$ & $\begin{array}{l}5.37 \\
5.37\end{array}$ & $\begin{array}{l}17.5 \\
19.2\end{array}$ \\
\hline
\end{tabular}




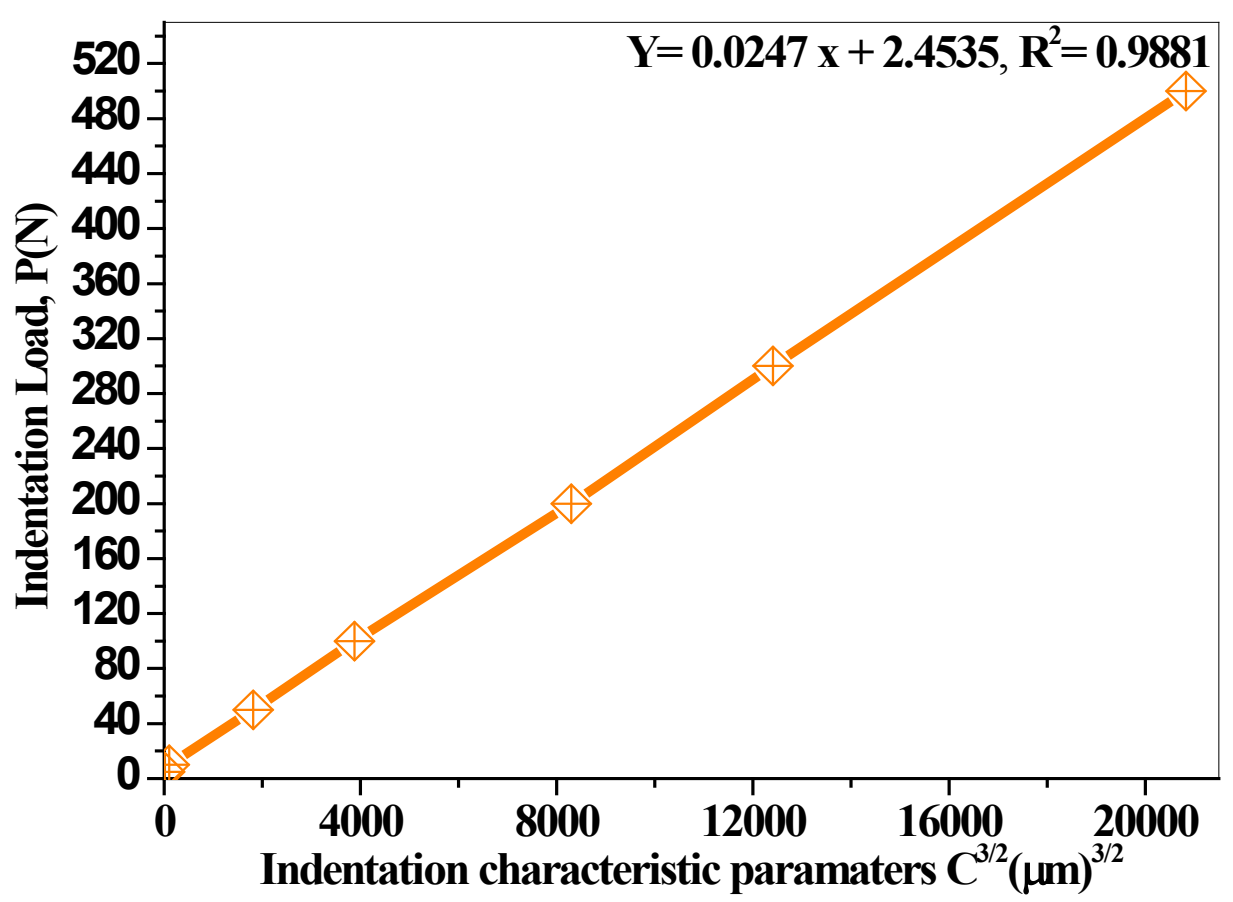

Figure 9. Correlation in between the applied load $\mathbf{P}$, and half-length of median crack $\mathbf{c}^{3 / 2}$ of $\mathbf{M T C}$ polished and etched surface for the sintered samples using a $\mathbf{2 0} \mathbf{~ m m}$ diameter die

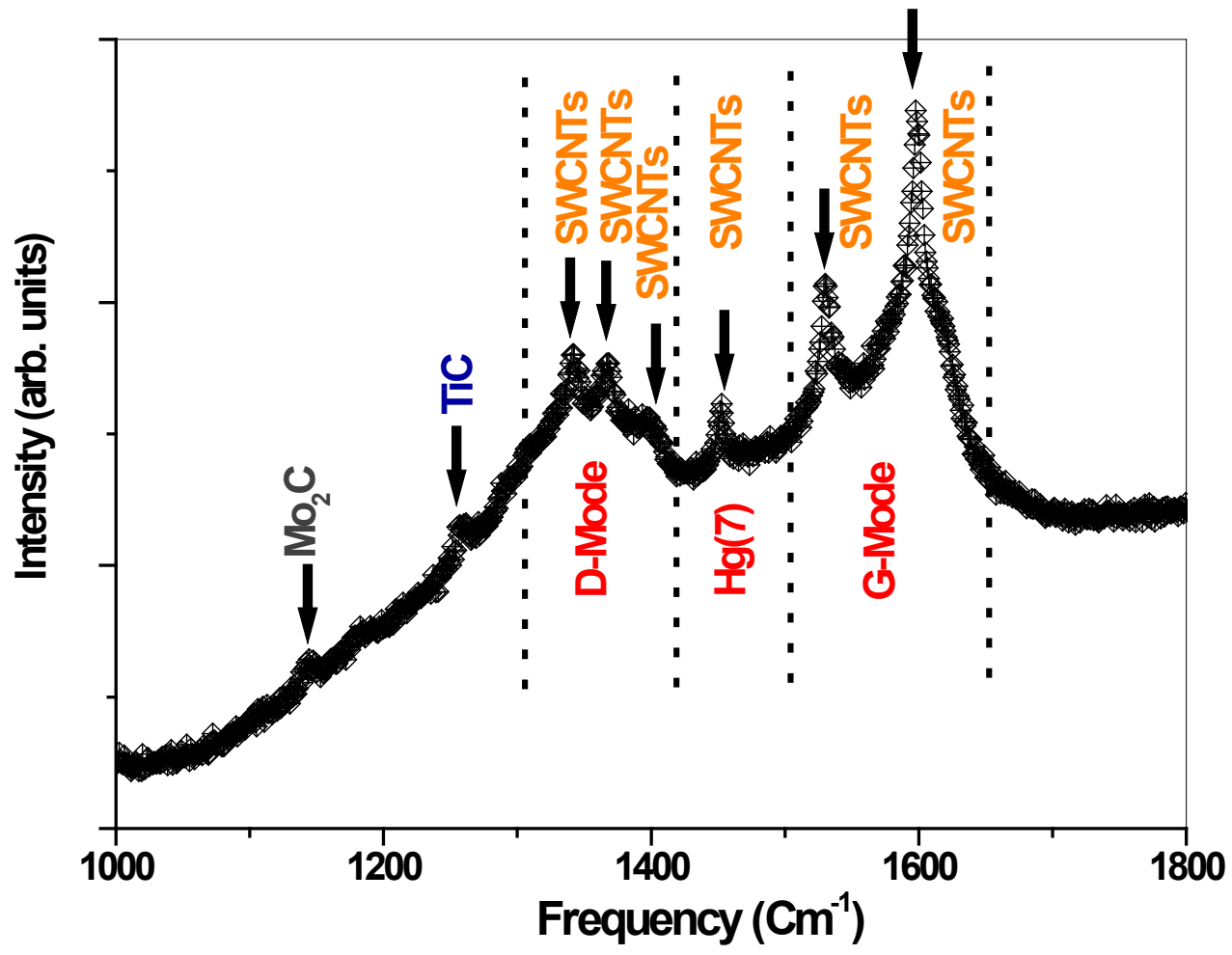

Figure 10. Raman spectra of the synthetized samples using a $\mathbf{2 0} \mathbf{~ m m}$ diameter die. 


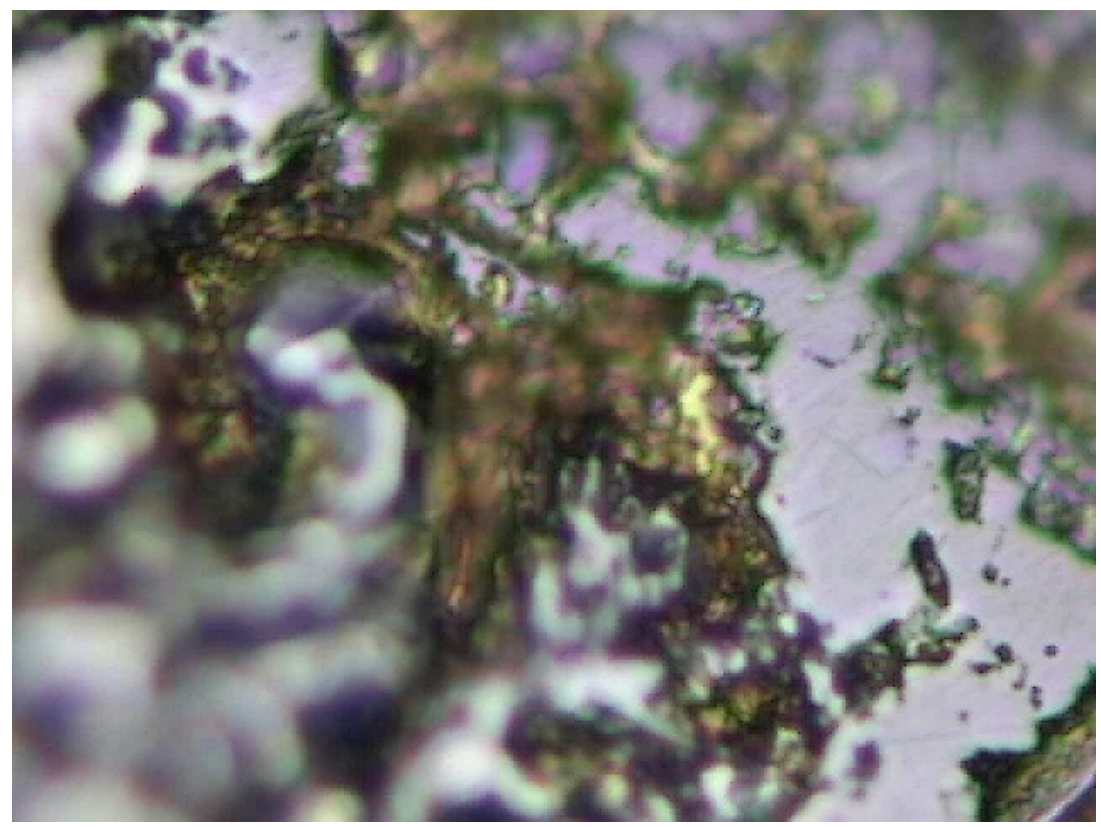

Figure 11. The explored nanocomposites regions

As a result, the calculated slope A and intercept $\mathbf{B}$ were $\mathbf{0 . 0 2 4 7}$ and 2.4535, respectively. The indentation fracture toughness was calculated to be $\mathbf{5 . 3 7} \mathrm{MPa} \mathbf{m}^{1 / 2}$ for $M_{0.8} T_{0.2} / \mathbf{1 W t} \%$ SWCNTs

The addition of SWCNTs play a important binderless role (the ductility) in the propagation of failler in this (NCMC's) and thus enhance the fracture toughness in comparison with his higher hardness In addition, a high determination coefficient $\left(\mathbf{R}^{2}\right)$ of $\mathbf{0 . 9 8 8 1}$ was obtained through the linear regression model [40].

IF (indentation fracture) was shown to be an effective method in the evaluation of fracture toughness for its convenience and materials saving.

\subsection{Raman Spectroscopy of $M_{1-x} T_{x}(2 \leq x \leq 4) / 1 W t \%$ SWCNTs, (NCMC's)}

In the Figure 10 and 11 is presented the Raman response of the (NCMC's), $M_{0.8} T_{0.2} / \mathbf{1 W t} \%$ SWCNTs, TiC and $\mathbf{M}_{0.6} \mathbf{T}_{\mathbf{0 . 4}}$. The $\mathbf{T i C}$ and $\mathbf{M o}_{2} \mathbf{C}$ vibration response are detected around the 1256 and $\mathbf{1 1 4 4} \mathbf{~ c m}^{-1}$ respectively. The reinforced phase of the binderless SWCNTs is localized in the typical frequency of $\mathbf{G}$ mode, D mode and $\mathbf{H g}(7)$ at $(1828,1597),(1338,1367)$ and $1451 \mathrm{~cm}^{-1}$, respectively. The pics of the Raman spectra have confirm the XRD investigations.

\section{Conclusions}

Several quantities of TiC ultrafine powder were added to the $S P S$ sintered dense $M_{1-\mathrm{x}} T_{\mathbf{x}}(2 \leq \mathrm{x} \leq 4) / \mathbf{1 W t} \%$ SWCNTs (MTC), (NCMC's) at $\mathbf{1 7 0 0}^{\circ} \mathrm{C}$ under a pressure of $70 \mathrm{MPa}$ for $10 \mathrm{~min}$ in pure $\mathrm{Ar}$ atmosphere protection. Phase analysis using XRD and EDX indicated that binderless fines powders $\mathbf{M o}_{2} \mathbf{C}, \mathbf{T i C}$ and un-reacted binder phase
SWCNTs were the main products. Microstructural observations by SEM showed that the effect of SWCNTs as binder phase make interface into $\mathbf{T i C}$ grains and good physical (relative density) and mechanical properties (Vickers hardness, young's modulus and fracture toughness) of (NCMC's) are obtain for $\mathbf{x}=\mathbf{0 . 2}$, $M_{0.8} T_{0.2} / \mathbf{1 W t} \%$ SWCNTs, SPS produced samples. The loss of SWCNTs during or conversion of SWCNTs to DWCNTs or MWCNTs the sintering processes are marqued by the holes like structure in the SEM pictures.

The challenge is to find efficiency methods for mixing of SWCNTs with the matrix composite. I suggest that SWCNTs will be metalized before mixing and sintering for minimizing their loss at high temperature.

The best density $99.5 \%$ and ductility of the nanocomposites $M_{0.8} T_{0.2} / \mathbf{1 W t} \%$ SWCNTs are obtained with the addition of the binderless reinforts phases of SWCNTs and TiC.

The fracture toughness are enhanced (ductile (NCMC's) $\mathbf{K}_{\mathrm{IC}}=5.6 \mathrm{Mpa}^{1 / 2}$ in comparison with his highest Vickers hardness. The Raman responses confirm the XRD investigations of the sintered samples.

Furthers measurements will be carried out with the nanoindentation technics, friction coefficient and wear resistance. Also furthers studies also will be performed with variation of the graphite die diameter, to control the SWCNTs content in the (NCMC's), MTC.

By Field Activated Sintering Technique (SPS), the extensive volume expansion as a function of the pressure will occur.

\section{Acknowledgements}

We are grateful to M. Aurélien Lepeutrec and M. 
Brahim Itaalit from LUSAC, EA 4253, Université de Caen Basse-Normandie (UCBN), Cherbourg-Octeville, France for the helps in the XRD, SEM.

\section{REFERENCES}

[1] M. J. Pitkethy, "Nanoparticles as building blocks?" Materials Today, vol. 6, no. 12, supplement 1(2003)36.

[2] K.R. Anderson, J.R. Groza, M. Fendorf, C.J. Echer, Mater. Sci. Eng. A 270 (1999)278.

[3] B. McWilliams, A. Zavalinagos, K.C. Cho, R.J. Dowding, J. Met. 58 (2006)67.

[4] Y. Zhou, K. Hirao, Y. Yamauchi, S. Kanzaki, Scripta Mater. 48 (2003)1631.

[5] W.D. Jones, Met. Ind. (1940)69.

[6] G. Degroat, Am. Mach. 109 (1965)107.

[7] S. Bangs, Prec. Met. 27 (1969)51.

[8] R.W. Boesel, M.I. Jacobson, I.S. Yoshioka, Mater. Eng. 70 (1969)32.

[9] K. Matsugi, N. Ishibashi, T. Hatayama, O. Yanagisawa, Intermetallic 4 (1996)6412.

[10] A. Hirata, H. Zheng, M. Yoshikawa, Diam. Relat. Mater. 7 (1998)1669.

[11] K. Inoue, U.S. Patent 3,241,956, March (1966).

[12] H. Honda, K. Kobayashi, K. Inoue, M. Ishiyama, Carbon 5 (1967) 545.

[13] K. Inoue, U.S. Patent 3,508,029, April (1970).

[14] C.G. Goetzel, V.S. De Marchi, Powder Metall. Int. 3 (1971) 80.

[15] C.G. Goetzel, High Temp.-High Press. 3 (1971)425.

[16] S. Saito, A. Sawaoka, Powder Metall. Int. 5 (1973)70.

[17] E.V. Rymorov, V.M. Kogan, I.D. Radomysel'skii, Sov. Powder Metall. Met. Ceram.13 (1974)587.

[18] T. Sakai, Z. Hara, J. Powder Bulk Solids Technol. 1 (1977)30.

[19] G.A. Weissler, J. Powder Bulk Solids Technol. 2 (1978)38.

[20] K. Akechi, Z. Hara, Trans. Jpn. Inst. Met. 20 (1979)51.
[21] G.A. Weissler, Int. J. Powder Metall. Powder Technol. 17 (1981)107.

[22] K. Hanawa, Z. Hara, K. Akechi, Trans. Jpn. Inst. Met. 22 (1981)449.

[23] M. Wada, F. Yamashita, IEEE Trans. Magn. 26 (1990)2601.

[24] J.R. Groza, S.H. Risbud, K. Yamanaki, J. Mater. Res. 7 (1992) 2463.

[25] S. Yoo, J.R. Groza, T.S. Sudarshan, K. Yamazaki, Scripta Mater. 34 (1996)1383.

[26] A. Kamiya, J. Mater. Sci. Lett. 17 (1998)49.

[27] C.M. Wang, M. Mitomo, F.F. Xu, N. Hirosaki, Y. Bando, J. Am. Ceram. Soc. 84 (2001)1389.

[28] A.I. Raichenko, E.S. Chernikova, E.A. Olevsky, J. Phys. IV 3 (1993) 1235

[29] J.A. Schneider, A.K. Mukherjee, K. Yamazaki, K. Shoda, Mater. Lett. 25 (1995)101.

[30] T. Nishimura, M. Mitomo, H. Hirotsuru, M. Kawahara, J. Mater. Sci. Lett. 14(1995)1046.

[31] Z. Wang, M. Matsumoto, T. Abe, K. Oikawa, T. Takagi, J. Qiu, J. Tani, Mater. Trans .JIM 40 (1999)863.

[32] S. Hoshii, A. Kojima, M. Goto, Carbon 38 (2000)1896.

[33] H.T. Kim, M. Kawahara, M. Tokita, J. Jpn. Soc. Powder Powder Metall. 47 (2000)887.

[34] T. Takeuchi, Y. Takeda, R. Funahashi, T. Aihara, M. Tabuchi, H. Kageyama, J. Electrochem. Soc. 147 (2000)3979.

[35] E.M. Heian, S.K. Khalsa, J.W. Lee, Z.A. Munir, T. Yamamoto, M. Ohyanagi, J. Am. Ceram. Soc. 87 (2004)779.

[36] A. Bellosi, F. Monteverde, D. Sciti, Int. J. Appl. Ceram. Technol. 3 (2006) 32.

[37] B. Basu, T. Venkateswaran, D.Y. Kim, J. Am. Ceram. Soc. 89 (2006) 2405.

[38] F. Monteverde, C. Melandri, S. Guicciardi, Mater. Chem. Phys. 100 (2006)513.

[39] E. Rocha-Rangel, Fracture toughness determinations by means of indentation fracture, in: D.J. Cuppoletti (Ed.), Nanocomposits with Unique Properties and Applications in Medicine and Industry (2011)21.

[40] JianjunSha, JianLi, Shouhao Wang, Zhaofu Zhang, Yongchang Wang, Jixiang Dai, Materials and Design 107 (2016)520.

[41] M.P. Harmer, R.J. Brook, J. Br. Ceram. Soc., 80 (1981)147 